\title{
Bicentric Retrospective Analysis of en Bloc Resection and Muscularis Mucosae Detection Rate in Non- Muscle Invasive Bladder Tumors: A Real-World Scenario
}

Julian P. Struck • Mario W. Kramer · Olga Katzendorn • Marie C. Hupe · Tomasz Ozimek · Martin J. P. Hennig · Judith R. Wießmeyer · Christoph A. J. von Klot - Markus A. Kuczyk · Hans H. Kreipe · Axel S. Merseburger • Sven Perner • Franz F. Dressler

Received: August 30, 2020 / Accepted: October 8, 2020 / Published online: October 22, 2020

(C) The Author(s) 2020

\section{ABSTRACT}

Introduction: For risk stratification of nonmuscle invasive bladder cancer (NMIBC), the depth of stromal invasion can be further classified, where the lamina muscularis mucosae (MM) serves as a reference structure. While the overall identifiability of $\mathrm{MM}$ in standard

Julian P. Struck and Mario W. Kramer contributed equally to this work.

J. P. Struck $(\bowtie) \cdot$ M. W. Kramer · M. C. Hupe .

T. Ozimek · M. J. P. Hennig · J. R. Wießmeyer ·

A. S. Merseburger

Department of Urology, University-Hospital

Schleswig-Holstein, Campus Luebeck, Ratzeburger

Allee 160, 23538 Luebeck, Germany

e-mail: julian.struck@uksh.de

O. Katzendorn · C. A. J. von Klot · M. A. Kuczyk Department of Urology and Urologic Oncology, Medical School Hannover, Carl-Neuberg-Str. 1, 30625 Hannover, Germany

\section{H. H. Kreipe}

Institute of Pathology, Medical School Hannover, Carl-Neuberg-Str. 1, 30625 Hannover, Germany

S. Perner · F. F. Dressler

Institute of Pathology, University Medical Center Schleswig-Holstein, Campus Luebeck, Ratzeburger Allee 160, 23538 Luebeck, Germany

S. Perner

Institute of Pathology, Research Center Borstel, Leibniz Lung Center, Parkallee 1-40, 23845 Borstel, Germany transurethral specimens is low, en bloc resection may help in identification and overall orientation. The aims of this study were to report the detection rate of $\mathrm{MM}$ in en bloc resected bladder tumors (ERBT) and to provide realworld information on tissue stability and preservation of en bloc architecture during recovery and processing for histopathologic evaluation.

Methods: Thirty-four ERBT specimens were histologically re-evaluated with regard to $\mathrm{MM}$ detectability and structure as well as the presence of en bloc architecture and further histologic features. Associations with tumor size and energy source and within histologic parameters were assessed by standard Pearson's chi-squared analyses and Cramér's V effect size testing (V).

Results: The first parameter assessed was MM detection rate. In 19 out of 34 samples (56\%) MM was detectable: scattered in 9 cases $(26 \%)$, interrupted in 8 cases (24\%) and continuous in 2 cases $(6 \%)$. The second parameter assessed was preservation of en bloc architecture. In 11 out of 34 samples (32\%), en bloc architecture could not be confirmed, and these samples served as a reference group for the detection of MM. Preservation of en bloc architecture was associated with an increased MM detection rate (MM in en bloc preserved $16 / 23,70 \%$ vs. non-preserved $3 / 11,27 \% ; p=0.020 ; V=0.398)$ and with tumor size $(p=0.005 ; V=0.595)$. Medium-sized tumors $(1.1-2 \mathrm{~cm})$ were best preserved. The choice of energy source did not 
show relevant association with en bloc architecture ( $p=$ n.s.).

Conclusions: In line with recent publications, ERBT increases the MM detection rate considerably. However, a third of the ERBT specimens lost en bloc architecture during sample recovery and processing. Tumor size is a relevant factor, with optimal architecture preservation between 1 and $2 \mathrm{~cm}$. Optimizing resection techniques, recovery, transport, and diagnostic processing of ERBT samples is warranted to verify the diagnostic value of MM-based substaging.

Keywords: Bladder cancer; En bloc; ERBT; Histopathologic stratification; Substaging

\section{Key Summary Points}

Why carry out this study?

Recurrent T1 bladder tumors exhibit a higher risk of progression and metastatic disease. Tumor subclassification (T1a-T1c) based on the relation of the tumor to the lamina muscularis mucosae $(\mathrm{MM})$ is possible.

The objectives of this study were to report the real-world rate of en bloc resected (ERBT) specimens that could be maintained in en bloc architecture during recovery and processing for histopathologic evaluation and to assess associations with tumor size and stage.

\section{What was learned from the study?}

ERBT increases the MM detection rate considerably.

A third of the ERBT specimens lost en bloc architecture during sample recovery and processing.

Tumor size is a relevant factor for architecture preservation (optimum between 1 and $2 \mathrm{~cm}$ ).
Optimizing resection techniques, recovery, transport, and diagnostic processing of ERBT samples is warranted to verify the diagnostic value of MM-based substaging.

\section{DIGITAL FEATURES}

This article is published with digital features, including a summary slide, to facilitate understanding of the article. To view digital features for this article go to https://doi.org/10.6084/ m9.figshare.13056314.

\section{INTRODUCTION}

Urothelial carcinoma of the bladder presents as an aggressive disease and is associated with high morbidity and mortality rates if it is not treated optimally [1]. Accurate histopathologic staging and grading are crucial in disease management. Thereby, the majority of patients initially present with non-muscle invasive bladder cancer (NMIBC) limited to the mucosa (Ta) or submucosa (T1). These tumors show significantly lower mortality compared to the muscle-invasive stages [2-4]. Nevertheless, recurrent T1 tumors exhibit a higher risk of progression and metastatic disease $[4,5]$. These tumors can be further classified based on the relation of the tumor to the lamina muscularis mucosae (MM), defining stages T1a-T1c [6]. Apart from tumor infiltration depth or invasive focus diameter, which are measured by micrometry [7-9], infiltration of the lymphovascular plexus (LVP) $[10,11]$ or the MM [10-12] has been proposed. $\mathrm{MM}$ is a layer of smooth muscle bundles delineating the lamina propria and submucosa in the bladder wall and can be used as an anatomical landmark for invasion depth. In this context, T1a is defined as tumor invasion above the MM, $\mathrm{T} 1 \mathrm{~b}$ as MM invasion and T1c as invasion across the MM (Fig. 1). Although this concept dates back to the 1980s $[13,14]$ and was further supported by a recent systematic meta-analysis [15], it has not yet been adopted in routine clinical practice. 

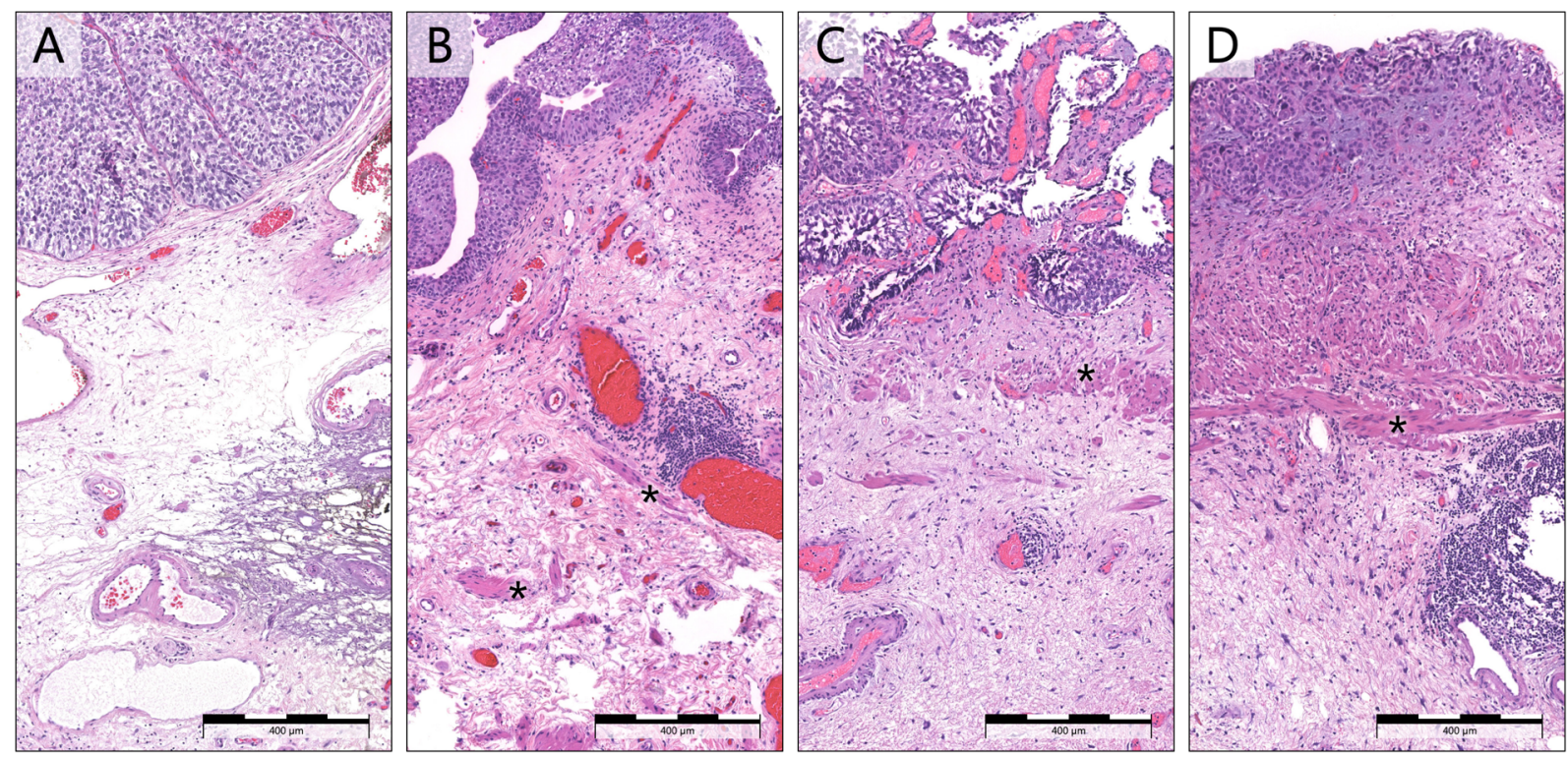

Fig. 1 Histomorphologic muscularis mucosae (MM) variants. Hematoxylin-eosin stains in $10 \times$ magnification; asterisk denotes MM fibers. a Absent; $\mathbf{b}$ scattered; $\mathbf{c}$ interrupted; $\mathbf{d}$ continuous

The objectives of this study were to report the real-world rate of en bloc resected (ERBT) specimens that could be maintained in en bloc architecture during recovery and processing for histopathologic evaluation and to assess associations with tumor size and stage. Futhermore, the association between MM detection and en bloc confirmation has been investigated and the frequencies of different types reported. Post hoc analyses were stipulated to further define associations of en bloc confirmation and $\mathrm{MM}$ detection with various parameters.

\section{METHODS}

A total of 34 specimens from two centers (Hanover Medical School and University Hospital Schleswig-Holstein, Campus Luebeck) were collected under exclusively attempted en bloc resection with three different energy sources from 2009 to 2019. No special preservation techniques have been applied. Upon completion of routine diagnostics in the pathologic institutes of Hanover and Luebeck, the samples were histomorphologically re-evaluated by two pathologists not involved with the primary diagnosis. En bloc architecture, as well as the existence and structure of MM, was examined. MM constitution was defined as scattered (spots), interrupted or continuous (Fig. 1) [14]. Preservation of en bloc architecture was defined as microscopic confirmation of a coherent tumor structure without signs of fragmentation (Fig. 2). The clinical and diagnostic parameters assessed included tumor grade, stage, size and identifiabilty of MM, LVP, blood vessels, muscularis propria (MP), and energy source. As part of the real-world scenario and to avoid selection bias, the study population had no specific selection criteria. Primary as well as recurrent non-muscle invasive bladder tumors were included. Institutional Review Board (IRB) approval was obtained from the Ethics Committee of the University of Luebeck (no. 18-056). Statistical analyses of contingency tables were performed using Pearson's chisquared test. Effect size was determined by calculating Cramér's V $(V)$ [16] to evaluate the association between clinicopathologic features and the identification rate of MM and preservation (confirmation) of en bloc architecture, respectively. Effect size was defined as small for $V=0.1$, medium for $V=0.3$ and large for $V=0.5$ [17]. For the primary hypotheses of the study, the significance level was set to $\alpha=0.05$; 

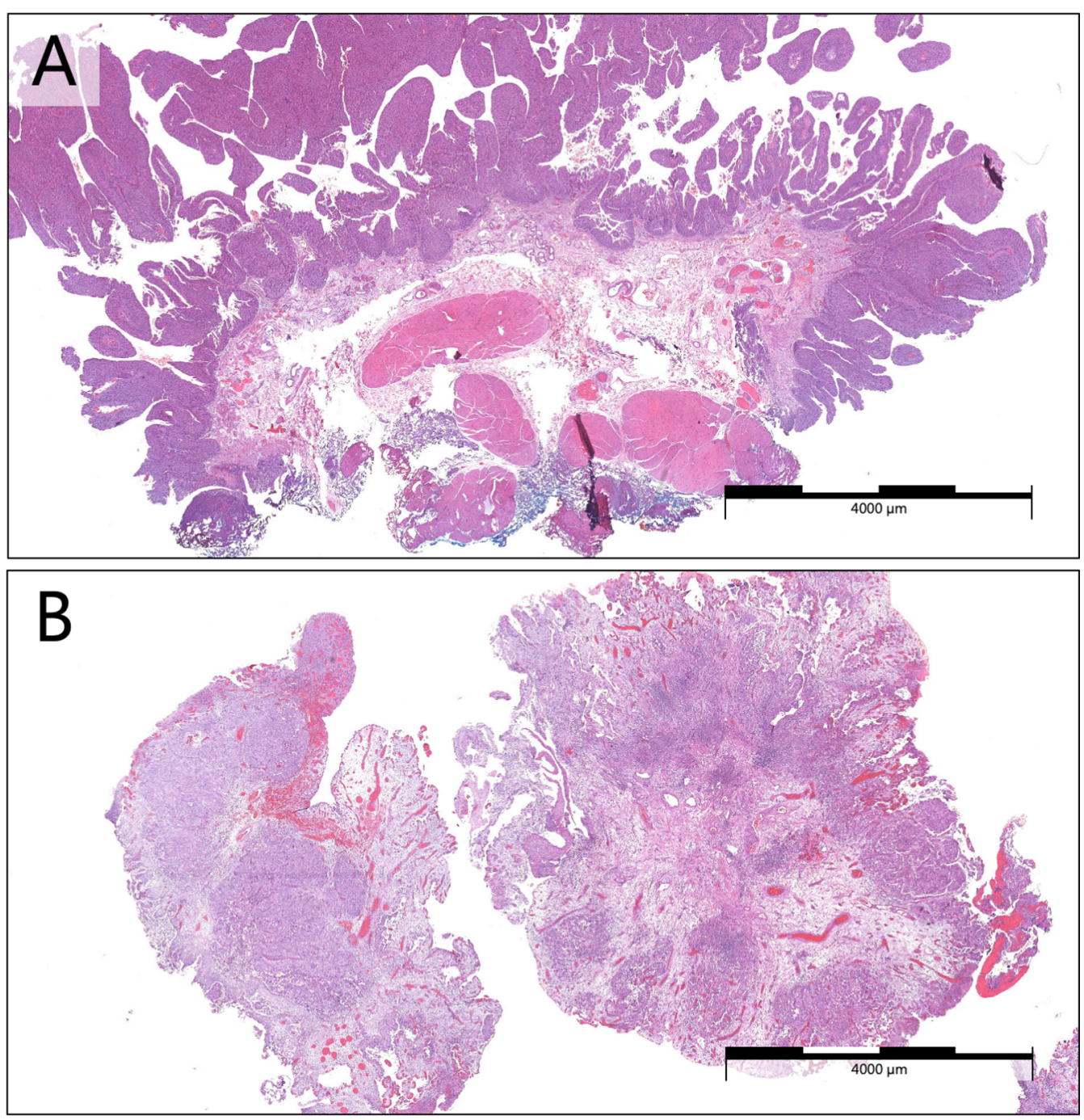

Fig. 2 En bloc resection versus fragmented architecture. Hematoxylin-eosin stains in $1.3 \times$ magnification. a En bloc resection of a papillary tumor preserves architecture and facilitates orthogonal orientation. b In contrast, fragments

for further secondary post hoc analyses, $\alpha$ was divided by the number of analyses performed according to the Bonferroni method [18, 19]. SPSS v26.0 was used (IBM Corp., Armonk, NY, USA) for all analyses and data management.

\section{RESULTS}

The majority of patients were male (91\%) with a median age at time of ERBT of 68.5 years (range are more difficult to orientate with a higher share of tangential cross sections, which impede determination of actual tumor infiltration depth

38-83 years). Detailed descriptive statistics are presented in Table 1.

In 11 out of 34 ERBT samples (33\%), en bloc architecture could not be confirmed, and these samples served as a reference group for the detection of MM. Tumor size was relevantly associated with en bloc confirmation ( $p=0.005$; $V=0.595$; Table 2), whereas invasiveness (pTa vs. pT1) was not (non-invasive 19/28 vs. invasive $4 / 6 ; p=0.955=$ n.s.). Of the 34 samples, 15 cases showed no MM (44\%), 9 cases showed 
Table 1 Descriptive statistics

\begin{tabular}{|c|c|c|}
\hline & $\begin{array}{l}\text { Number } \\
(n=34)\end{array}$ & $\begin{array}{l}\text { Percentage } \\
(\%)\end{array}$ \\
\hline \multicolumn{3}{|l|}{ Age in years } \\
\hline$>70$ years & 15 & 44.1 \\
\hline$<70$ years & 19 & 55.9 \\
\hline \multicolumn{3}{|l|}{ Sex } \\
\hline Male & 31 & 91.2 \\
\hline Female & 3 & 8.8 \\
\hline \multicolumn{3}{|l|}{ Tumor grade } \\
\hline High & 12 & 35.3 \\
\hline Low & 20 & 58.8 \\
\hline Benign & 2 & 5.9 \\
\hline \multicolumn{3}{|l|}{ Tumor stage } \\
\hline $\mathrm{pTa}$ & 26 & 76.5 \\
\hline pT1 & 6 & 17.6 \\
\hline Benign & 2 & 5.9 \\
\hline \multicolumn{3}{|l|}{ Tumor multifocality } \\
\hline Single & 29 & 85.3 \\
\hline Multiple & 5 & 14.7 \\
\hline \multicolumn{3}{|l|}{ Size } \\
\hline$<1 \mathrm{~cm}$ & 11 & 32.4 \\
\hline $1.1-2 \mathrm{~cm}$ & 13 & 38.2 \\
\hline $2.1-3 \mathrm{~cm}$ & 6 & 17.6 \\
\hline$>3 \mathrm{~cm}$ & 4 & 11.8 \\
\hline \multicolumn{3}{|l|}{ Energy source } \\
\hline Thulium laser & 17 & 50.0 \\
\hline Electrocauterization & 11 & 32.4 \\
\hline HybridKnife & 6 & 17.6 \\
\hline \multicolumn{3}{|c|}{ Histomorphologic features } \\
\hline MP detectable & 28 & 82.4 \\
\hline MM detectable & 19 & 55.9 \\
\hline LVP detectable & 24 & 70.6 \\
\hline
\end{tabular}

Table 1 continued

\begin{tabular}{lll}
\hline & $\begin{array}{l}\text { Number } \\
(\boldsymbol{n}=\mathbf{3 4})\end{array}$ & $\begin{array}{l}\text { Percentage } \\
(\%)\end{array}$ \\
\hline $\begin{array}{l}\text { Confirmation of ERBT } \\
\text { architecture }\end{array}$ & 23 & 67.6 \\
\hline
\end{tabular}

scattered MM (26\%), 8 cases showed interrupted MM (24\%), and 2 cases showed continuous MM (6\%; Table 3). Sixteen out of 23 samples with en bloc architecture showed an identifiable MM (70\%) compared to 3 out of 11 samples in the non-confirmed group $(27 \% ; \quad p=0.020$; $V=0.398$; Table 4). Examples of the different types of MM are given in Fig. 1.

For six further post hoc analyses, the signifcance level $\alpha$ was Bonferroni-adjusted to 0.008. There was a trend towards an association of tumor size with better MM detection but no significance $(p=0.043=$ n.s.; Table 5$)$. Tumor invasiveness was not associated with $\mathrm{MM}$ detection (MM in non-invasive $14 / 28$ vs. invasive $5 / 6 ; p=0.196=$ n.s.), nor was the type of energy source during resection $(p=0.155=$ n.s.; Table 5). Confirmation of en bloc architecture was not associated with higher detection rates of MP (MP-positive 19/28 vs. MP-negative 4/6; $p=0.955=$ n.s. $) \quad$ or $\operatorname{LVP} \quad(5 / 10 \quad$ vs. $18 / 24$; $p=0.232=$ n.s.). There was a trend toward an association between energy source and en bloc confirmation itself but no significance $(p=0.043=$ n.s. $)$.

\section{DISCUSSION}

While the correct identification of $\mathrm{MM}$ is relevant to avoid under- or overstaging, respectively [13], its detection is hampered in conventional, transurethrally obtained specimens (cTURB) [6]. Sample orientation, tangential section plane and cauterization of the sample margin can render morphologic distinction between detrusor muscle and MM difficult. Immunohistochemistry may be of some, but often little, help [20] and may require cross-marker analyses [21]. Furthermore, MM hypertrophy can mimic MP [22]. 
Table 2 Tumor size vs. preserved en bloc architecture

\begin{tabular}{lccc}
\hline & \multicolumn{2}{l}{ Confirmation en bloc architecture } & Total \\
\cline { 2 - 3 } & Yes & No & \\
\hline Tumor size & & 6 & 11 \\
$<1 \mathrm{~cm}$ & 5 & 0 & 13 \\
$1.1-2 \mathrm{~cm}$ & 13 & 2 & 6 \\
$2.1-3 \mathrm{~cm}$ & 4 & 3 & 4 \\
$>3 \mathrm{~cm}$ & 1 & 11 & 34 \\
Total & 23 & & \\
\hline
\end{tabular}

Apart from these diagnostic limitations, which impede histopathologic examination [23], cTURB can lead to tumor fragmentation. To some extent, this also opposes the widespread oncologic principle to preserve tumor

Table 3 Muscularis mucosae (MM) types and energy source

\begin{tabular}{llll}
\hline MM type & Energy source & Number & Percent \\
\hline Absent & Any & $15 / 34$ & 44 \\
& Electric & $8 / 11$ & 73 \\
& Thulium laser & $6 / 17$ & 35 \\
& Hybrid knife & $1 / 6$ & 17 \\
Scattered & Any & $9 / 34$ & 26 \\
& Electric & $3 / 11$ & 27 \\
& Thulium laser & $4 / 17$ & 24 \\
& Hybrid knife & $2 / 6$ & 33 \\
Interrupted & Any & $8 / 34$ & 24 \\
& Electric & $0 / 11$ & 0 \\
& Thulium laser & $6 / 17$ & 35 \\
& Hybrid knife & $2 / 6$ & 33 \\
Continuous & Any & $2 / 34$ & 6 \\
& Electric & $0 / 11$ & 0 \\
& Thulium laser & $1 / 17$ & 6 \\
& Hybrid knife & $1 / 6$ & 17 \\
\hline
\end{tabular}

integrity and prevent tumor cell seeding $[24,25]$. After cTURB, residual tumor rates of $30-55 \%$ in pT1 and $20-40 \%$ in pTa tumors lead to the guideline recommendation of re-resection within 8 weeks $[3,4]$. En bloc resection of NMIBC, which in contrast to cTURBT starts at the tumor base, represents an optimized technique to raise the quality of histopathologic samples and to avoid unneccessary spread of tumor cells, as recently described by the authors (Fig. 2) [26-28]. Optimal diagnostic utilization of its benefits could lead to a better substaging of initial invasion with more reliable predictions for recurrence and progression rates, avoiding unnecessary re-resections in the future $[15,23,25,29]$.

In line with a recent publication by Liang et al. [30], there was a significant and relevant increase in the MM detection rate in ERBT specimens, up to almost three in four samples compared to $27 \%$ where en bloc architecture could not be preserved. While the same group reported an association of higher tumor grade and stage with an increased identification rate of MM, we could not find such a link in our data. However, when MM could be identified, half of the samples showed only scattered muscle fibers, possibly reducing diagnostic usability as a reference structure. In a real-world setting, we found a preservation rate of en bloc architecture in two thirds of all samples (Fig. 2). Together with the association of en bloc structure with $\mathrm{MM}$ detection, this underlines the importance of keeping the sample intact during recovery and processing. In line with a recently published international consensus statement which concluded that after ERBT additional biopsy of the tumour edge or tumour base should not be performed routinely, the MM detection rate in these specimens was not the objective of this study [29].

We could identify tumor size as a relevant factor with complete preservation of en bloc integrity between 1 and $2 \mathrm{~cm}$, hinting at intraoperative recovery (flushing, forceps, recovery bags, etc.) as one of the main factors. Consequently, larger tumors may prove more difficult to preserve en bloc. The use of macroscopic orientation aids, such as color or clips, might raise preservation rates in smaller specimens 
Table 4 Tumor size vs. muscularis mucosae (MM) detection in en bloc resection (ERBT) subgroups

\begin{tabular}{|c|c|c|c|c|c|c|c|c|}
\hline & \multicolumn{8}{|c|}{ Confirmation en bloc architecture } \\
\hline & \multicolumn{4}{|l|}{ Yes } & \multicolumn{4}{|l|}{ No } \\
\hline & \multicolumn{4}{|c|}{ MM detection } & \multicolumn{4}{|c|}{ MM detection } \\
\hline & No & & Yes & & No & & Yes & \\
\hline \multicolumn{9}{|l|}{ Tumor size } \\
\hline$<1 \mathrm{~cm}$ & 2 & $(40 \%)$ & 3 & $(60 \%)$ & 4 & $(67 \%)$ & 2 & $(33 \%)$ \\
\hline $1.1-2 \mathrm{~cm}$ & 3 & $(23 \%)$ & 10 & $(77 \%)$ & 0 & $(0 \%)$ & 0 & $(0 \%)$ \\
\hline $2.1-3 \mathrm{~cm}$ & 1 & $(25 \%)$ & 3 & $(75 \%)$ & 1 & $(50 \%)$ & 1 & $(50 \%)$ \\
\hline$>3 \mathrm{~cm}$ & 1 & $(100 \%)$ & 0 & $(0 \%)$ & 3 & $(100 \%)$ & 0 & $(0 \%)$ \\
\hline Total & 7 & & 16 & & 8 & & 3 & 34 \\
\hline
\end{tabular}

Table 5 Tumor size vs. muscularis mucosae (MM) detection

\begin{tabular}{lccc}
\hline & \multicolumn{2}{l}{ Muscularis mucosae detection } & Total \\
\cline { 2 - 3 } & Yes & No & \\
\hline Tumor size & & 6 & 11 \\
$<1 \mathrm{~cm}$ & 5 & 3 & 13 \\
$1.1-2 \mathrm{~cm}$ & 10 & 2 & 6 \\
$2.1-3 \mathrm{~cm}$ & 4 & 4 & 4 \\
$>3 \mathrm{~cm}$ & 0 & 15 & 34 \\
\hline Total & 19 & & \\
\hline
\end{tabular}

during subsequent processing. The role of intraoperative recovery processes in preservation of ERBT tissue integrity therefore needs further examination. The lower preservation rate in smaller tumors could be explained by the generally more difficult macroscopic sample orientation in small specimens during diagnostic processing. To investigate whether tumor size was a considerable confounder for the higher detection rate in ERBT specimens, its association with MM detection was tested and was found to be non-significant. This was in line with the actual distribution of MM-positive samples in the respective size subgroups (Table 4). Our previous meta-analysis confirmed that all energy devices (lasers, electric cautery) have been used to perform ERBT with similar perioperative and oncologic outcomes [26]. Therefore, choice of energy source was left a surgeon's decision as part of the real-world setting. We investigated the influence of the energy source on the ERBT procedure but could not find a relevant effect. Liang et al. performed ERBT exclusively with a front-firing greenlight laser, which shows a high spray effect and can cause coagulation artifacts. In contrast, the ERBT procedures in our study were performed using a thulium:YAG laser or electric resection with or without a hybrid knife. Most of the literature dealing with laser ERBT (l-ERBT) used the thulium:YAG laser [26, 27]. Nevertheless, the use of these energy sources did not lead to higher MM detection rates in our study.

\section{CONCLUSIONS}

ERBT considerably improves the identifiability of the MM but requires increased attention not only during resection but also during intraoperative sample recovery and subsequent handling. When present, MM is most frequently scattered, which renders its usage as a reference structure for substaging more challenging. At the same time, this stresses the importance of optimal specimen orientation and tissue integrity. In this context, future prospective studies 
on ERBT are necessary, such as our ongoing prospective en bloc trial EBRUC II (German Study Reg. No. DRKS0002073).

\section{ACKNOWLEDGEMENTS}

Funding. No funding or sponsorship was received for this study or publication of this article.

Authorship. All named authors meet the International Committee of Medical Journal Editors (ICMJE) criteria for authorship for this article, take responsibility for the integrity of the work as a whole, and have given their approval for this version to be published.

Authorship Contributions. Struck JP (main author): project/protocol development, data collection, data management, data analysis, manuscript writing and editing. Kramer MW (main author): project/protocol development, data collection, data management, data analysis, manuscript editing. Katzendorn O: data collection, manuscript editing. Hupe MC: manuscript editing. Ozimek T: manuscript editing. Hennig MJP: manuscript editing. Wießmeyer JR: manuscript editing. Von Klot CAJ: manuscript editing. Kuczyk MA: manuscript editing. Kreipe $\mathrm{HH}$ : manuscript editing. Merseburger AS: manuscript editing. Perner S: project development, data analysis, manuscript editing. Dressler FF (senior author): Project development, data collection, data analysis, manuscript writing and editing.

Disclosures. The authors (Julian P. Struck, Olga Katzendorn, Marie C. Hupe, Tomasz Ozimek, Martin J. P. Hennig, Judith R. Wießmeyer, Christoph A. J. von Klot, Markus A. Kuczyk, Hans H. Kreipe, Sven Perner and Franz F. Dressler) have nothing to disclose. Prof. Merseburger and Dr. Kramer are editorial board members of Advances in Therapy but have nothing else to disclose.

Compliance with Ethics Guidelines. This article contains retrospective analyses of human histological specimens in accordance with the Declaration of Helsinki after all routine diagnostics were performed. A respective ethics approval was obtained from the ethics committee of the University of Luebeck (No. 18-056).

Data Availability. Access to associated data will be granted on request to the main or senior authors.

Open Access. This article is licensed under a Creative Commons Attribution-NonCommercial 4.0 International License, which permits any non-commercial use, sharing, adaptation, distribution and reproduction in any medium or format, as long as you give appropriate credit to the original author(s) and the source, provide a link to the Creative Commons licence, and indicate if changes were made. The images or other third party material in this article are included in the article's Creative Commons licence, unless indicated otherwise in a credit line to the material. If material is not included in the article's Creative Commons licence and your intended use is not permitted by statutory regulation or exceeds the permitted use, you will need to obtain permission directly from the copyright holder. To view a copy of this licence, visit http://creativecommons.org/licenses/by$\mathrm{nc} / 4.0 /$.

\section{REFERENCES}

1. Kamat AM, Hahn NM, Efstathiou JA, et al. Bladder cancer. Lancet. 2016;388(10061):2796-810.

2. Burger M, Catto JWF, Dalbagni G, et al. Epidemiology and risk factors of urothelial bladder cancer. Eur Urol. 2013;63(2):234-41.

3. Alfred Witjes J, Lebret T, Compérat EM, et al. Updated 2016 EAU guidelines on muscle-invasive and metastatic bladder cancer. Eur Urol. 2017;71(3):462-75.

4. Babjuk M, Böhle A, Burger M, et al. EAU guidelines on non-muscle-invasive urothelial carcinoma of the bladder: update 2016. Eur Urol. 2017;71(3):447-61. 
5. Grimm M-O, Steinhoff C, Simon X, Spiegelhalder P, Ackermann R, Vogeli TA. Effect of routine repeat transurethral resection for superficial bladder cancer: a long-term observational study. J Urol. 2003;170(2 Pt 1):433-7.

6. van de Putte EEF, Behrendt MA, Pigot GLS, van der Kwast TH, van Rhijn BWG. Prognostic significance of substage and WHO classification systems in T1 urothelial carcinoma of the bladder. Curr Opin Urol. 2015;25(5):427-35.

7. Cheng L, Weaver AL, Neumann RM, Scherer BG, Bostwick DG. Substaging of T1 bladder carcinoma based on the depth of invasion as measured by micrometer: a new proposal. Cancer. 1999;86(6): 1035-43.

8. Cheng L, Neumann RM, Weaver AL, Spotts BE, Bostwick DG. Predicting cancer progression in patients with stage T1 bladder carcinoma. J Clin Oncol. 1999;17(10):3182-7.

9. Colombo R, Hurle R, Moschini M, et al. Feasibility and clinical roles of different substaging systems at first and second transurethral resection in patients with T1 high-grade bladder cancer. Eur Urol Focus. 2018;4(1):87-93.

10. Brimo F, Wu C, Zeizafoun N, et al. Prognostic factors in $\mathrm{T} 1$ bladder urothelial carcinoma: the value of recording millimetric depth of invasion, diameter of invasive carcinoma, and muscularis mucosa invasion. Hum Pathol. 2013;44(1):95-102.

11. van Rhijn BWG, van der Kwast $\mathrm{TH}$, Alkhateeb SS, et al. A new and highly prognostic system to discern T1 bladder cancer substage. Eur Urol. 2012;61(2): 378-84.

12. Dixon JS, Gosling JA. Histology and fine structure of the muscularis mucosae of the human urinary bladder. J Anat März. 1983;136(Pt 2):265-71.

13. Ro JY, Ayala AG, El-Naggar A. Muscularis mucosa of urinary bladder. Importance for staging and treatment. Am J Surg Pathol. 1987;11(9):668-73.

14. Keep JC, Piehl M, Miller A, Oyasu R. Invasive carcinomas of the urinary bladder. Evaluation of tunica muscularis mucosae involvement. Am J Clin Pathol. 1989;91(5):575-9.

15. Martin-Doyle W, Leow JJ, Orsola A, Chang SL, Bellmunt J. Improving selection criteria for early cystectomy in high-grade $t 1$ bladder cancer: a metaanalysis of 15,215 patients. J Clin Oncol. 2015;33(6):643-50.

16. Cohen J. Statistical power analysis for the behavioral sciences. 2nd ed. Erlbaum Associates: Hillsdale; 1988. p. 567S.
17. Ellis PD. The essential guide to effect sizes: statistical power, meta-analysis, and the interpretation of research results [Internet]. Cambridge Core. Cambridge University Press, 2010. www.core/books/ essential-guide-to-effect-sizes/72C26CA99366A19C AC4EF5B16AE3297F. Cited 8 Mär 2020.

18. Schulz KF, Grimes DA. Multiplicity in randomised trials I: endpoints and treatments. Lancet. 2005;365(9470):1591-5.

19. Jafari M, Ansari-Pour N. Why, when and how to adjust your $p$ values? Cell J. 2019;20(4):604-7.

20. Lindh C, Nilsson R, Lindstrom ML, Lundin L, Elmberger G. Detection of smoothelin expression in the urinary bladder is strongly dependent on pretreatment conditions: a critical analysis with possible consequences for cancer staging. Virchows Arch Int J Pathol. 2011;458(6):665-70.

21. Elkady N, Abdou AG, Kandil M, Ghanem N. Diagnostic value of smoothelin and vimentin in differentiating muscularis propria from muscularis mucosa of bladder carcinoma. Int J Biol Mark. 2017;32(3):e305-12.

22. Vakar-Lopez F, Shen SS, Zhang S, Tamboli P, Ayala AG, Ro JY. Muscularis mucosae of the urinary bladder revisited with emphasis on its hyperplastic patterns: a study of a large series of cystectomy specimens. Ann Diagn Pathol. 2007;11(6):395-401.

23. Hansel DE, Amin MB, Comperat E, et al. A contemporary update on pathology standards for bladder cancer: transurethral resection and radical cystectomy specimens. Eur Urol. 2013;63(2): 321-32.

24. Ray ER, O'Brien TS. Should urologists be spending more time on the golf course? BJU Int. 2007;100(4): 728-9.

25. Wilby D, Thomas K, Ray E, Chappell B, O'Brien T. Bladder cancer: new TUR techniques. World J Urol. 2009;27(3):309-12.

26. Kramer MW, Altieri V, Hurle R, et al. Current evidence of transurethral en-bloc resection of nonmuscle invasive bladder cancer. Eur Urol Focus. 2017;3(6):567-76.

27. Struck JP, Karl A, Schwentner C, Herrmann TRW, Kramer MW. En bloc resection and vaporization techniques for the treatment of bladder cancer. Urol Ausg A. 2018;57(6):665-72.

28. Hennig MJP, Kramer MW. Potential for improvement by new resection and imaging techniques in TUR-B. Aktuelle Urol. 2020;51(4):348-52. 
29. Teoh JY-C, MacLennan S, Chan VW-S, et al. An international collaborative consensus statement on en bloc resection of bladder tumour incorporating two systematic reviews, a two-round Delphi survey, and a consensus meeting. Eur Urol. 2020;78:546.
30. Liang H, Yang T, Wu K, He D, Fan J. En bloc resection improves the identification of muscularis mucosae in non-muscle invasive bladder cancer. World J Urol. 2019;37(12):2677-82. 